\title{
ELETROGALVANIZAÇÃO NA INDÚSTRIA AUTOMOBILÍSTICA
}

\author{
Wandercleiton da Silva Cardoso ${ }^{1}$, Brena da Silva Porcino², Vitor Toniato Campana²
}

1Mestre em engenharia de materiais e metalurgia pelo Instituto Federal do Espírito Santo e docente nível superior dos cursos de engenharia da Faculdade Multivix.

2Graduando em engenharia mecânica Faculdade Multivix.

\begin{abstract}
RESUMO
A corrosão do aço é um problema recorrente, principalmente, em ambientes com alto teor de cloretos e nesse caso a galvanização eletrolítica é uma alternativa eficiente para proteger os aços contra a corrosão. O processo de galvanização eletrolítica acontece através do revestimento do aço com zinco durante a eletrólise do metal a ser revestido que funciona como catodo e o metal que irá revestir a peça funciona como ânodo. A solução eletrolítica deve conter um sal composto por cátions do metal que se deseja revestir a peça. No processo de galvanização eletrolítica a cobertura do substrato do aço é mais homogênea quando comparado com a galvanização por imersão a quente. No processo de galvanização eletrolítica o controle da espessura do revestimento depende do tempo que a peça fica imersa no banho de sais de zinco. Na galvanização eletrolítica contínua em chapas de aço é utilizado o mesmo princípio básico utilizado da galvanização eletrolítica convencional. Neste trabalho, foi feita uma avaliação dos benefícios da galvanização eletrolítica contínua de chapas de aço, mostrando que esses revestimentos apresentam aplicações singulares na indústria automotiva. Esses aços galvanizados apresentam superfícies de alta qualidade com massa entre 50 e $80 \mathrm{~g} / \mathrm{m}^{2}$ de zinco depositado no substrato, suficiente para atender às exigências relacionadas à corrosão. Os aços eletrogalvanizados são ideais para painéis de automóveis, principalmente, quando comparados aos produtos galvanizados por imersão à quente com mesma espessura que exige um processo de fabricação bem mais complexo.
\end{abstract}

Palavras-chave: Galvanização. Eletrolítica. Galvanoplastia. Corrosão. Aços. Galvanizados.

\begin{abstract}
Corrosion of steel is a common problem in environments with high levels of chlorides and these electroplating environments is an efficient alternative to protect steel from corrosion. The electroplating process occurs through the steel casing with zinc metal during the electrolysis to be coated which acts as cathode and the metal will coat the piece serves as the anode. The electrolyte solution must include a salt composed of zinc cations to be able to coat the steel. In the electroplating process, the steel substrate coverage is more homogeneous compared to hot-dip galvanized. In the electroplating process, control of coating thickness depends on the time that the piece is immersed in the zinc salt solution. In continuous electroplating steel plates is used the same basic principle used in conventional electroplating. This paper an evaluation of the benefits of continuous electroplating steel plate and it was shown that these coatings have unique applications in the automotive industry. These electrogalvanized steels have high quality surfaces with mass $50-80 \mathrm{~g} / \mathrm{m}^{2}$ zinc deposited on the substrate, sufficient to meet the requirements related to corrosion. The electrogalvanized steels are ideal for automobile panels, especially when compared to products by hot-dip galvanized with the same thickness requires a fabrication process much more complicated.
\end{abstract}

Keywords: Electrolytic. Galvanizing. Electroplating. Corrosion. Galvanized. Steel. 


\section{INTRODUÇÃO}

A corrosão do aço é um problema global e recorrente, principalmente, em ambientes com alto teor de cloretos e anualmente os custos com corrosão representam cerca de $4 \%$ o PIB das nações industrializadas, e em média $5 \%$ está na economia dos países emergentes. No ano passado (2013) o PIB do Brasil foi de $\mathrm{R} \$ 4,84$ trilhões, ou seja, a perda por corrosão considerando $5 \%$ do PIB representa um valor total de $R \$ 242$ bilhões (AGA, 2016).

Uma das maiores mudanças ocorridas nos últimos anos em relação à aplicação do aço como elemento estrutural, foi a utilização de aços revestidos com zinco para situações que exigem maior resistência à corrosão. A pressão dos usuários finais e dos fabricantes, que ocorreu na década de 80 , foram as principais responsáveis por esse aumento do uso de aços galvanizados. (SERE, DEYA \& SARLI, 2016)

A forma clássica de prevenção da oxidação foi, por muitos anos, a pintura. Atualmente, aços de maior valor agregado vêm ganhando mercado. É o caso dos aços revestidos com zinco, também conhecidos como galvanizados. O zinco tem a missão de se "sacrificar" para proteger o aço. Isso acontece porque o zinco é mais anódico e se corrói, originando uma proteção catódica. (ROVENTI et al, 2014)

A galvanização eletrolítica é o processo de revestimento do aço com zinco através da eletrólise onde o metal a ser revestido funciona como catodo e o metal que irá revestir a peça funcionam como ânodo. A solução eletrolítica deve conter um sal composto por cátions do metal que se deseja revestir a peça. No processo eletrolítico a cobertura do substrato do aço é mais homogênea e o controle da espessura do revestimento se dá pela velocidade com que a peça passa pelo banho de sais de zinco. (TUTIKIANI, HILGERTI \& HOWLANDII, 2014).

\section{DESENVOLVIMENTO}

A galvanização eletrolítica continua em chapas de aço, utiliza o mesmo princípio básico utilizado da galvanização eletrolítica convencional. Entretanto, o processo para chapas de aço é diferente, pois o revestimento eletrogalvanizado é aplicado através da passagem da tira em alta velocidade por uma série de células de galvanização, aumentando a espessura do revestimento em pequenas quantidades cada vez que a tira passa por uma célula individual. (PEREZ et al, 2002)

Na galvanização eletrolítica o anodo é o zinco, o catodo é o aço e o eletrólito é o sulfato de zinco ou o cloreto de zinco. A energia elétrica é fornecida pela fonte de corrente contínua. No anodo, o zinco é oxidado e libera dois elétrons e se dissolve como cátion no eletrólito e no catodo de aço, cátions de zinco se combinam com dois elétrons (redução) e formam o zinco elementar, que se deposita sobre a superfície do aço. A solução de galvanização (eletrólito) carrega a corrente contínua entre o catodo e o anodo. (FAYALA el al, 2013)

O modelo esquemático da célula de galvanização que ocorre durante o processo de eletrogalvanização está ilustrada na figura 1. 
Figura 1 - Galvanização eletrolítica



No processo de galvanização eletrolítica contínua a operação se estende à galvanização de chapas de aço muito longas, superiores a 70 polegadas de largura. No processo eletrolítico contínuo uma série de células galvânicas como mencionado na figura 1 são alinhadas em sequência e as chapas de aços passam por estas células eletroquímicas em altas velocidades e cada conjunto anodo/catodo é conectado a uma fonte de energia. As chapas de aço são transportadas através de cilindros e motores e uma desbobinadeira na extremidade na entrada da linha é responsável em introduzir a chapa bobinada na seção de processamento e uma rebobinadeira na extremidade final da linha para reenrolar a chapa em uma bobina. (CABANELAS, 2007)

O modelo esquemático do processo de galvanização eletrolítica continua é mostrado na figura 2.

Figura 1 - Galvanização eletrolítica contínua

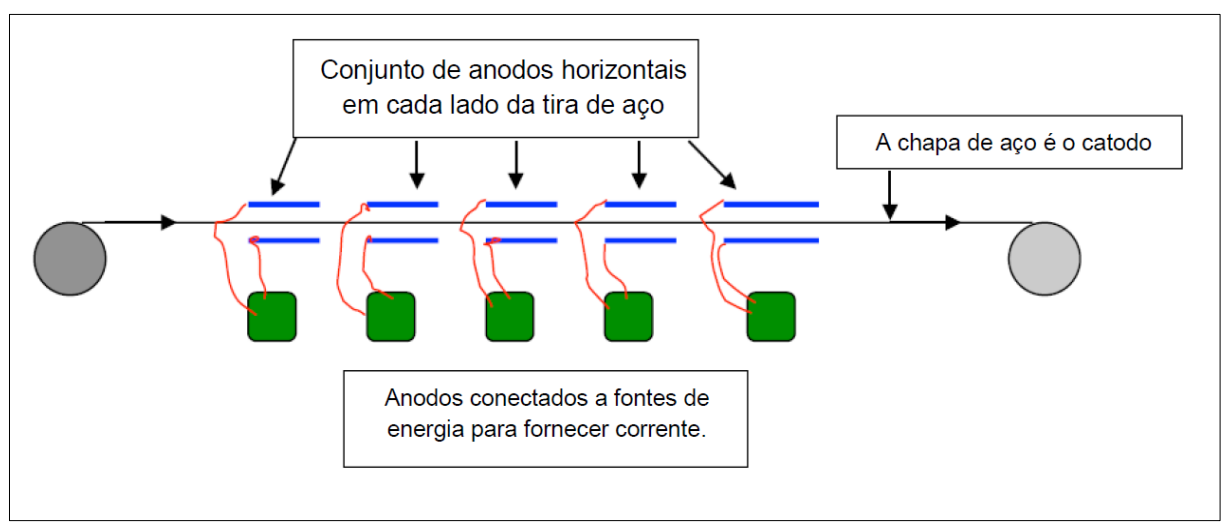

O processo de eletrogalvanização exige uma grande quantidade de energia elétrica para a aplicação de revestimentos de zinco. A exigência total de energia é uma função direta da espessura do revestimento que é necessária para atender às especificações do cliente. Por exemplo, a energia necessária para depositar uma massa de revestimento de zinco de 80 
$\mathrm{g} / \mathrm{m}^{2}$ é aproximadamente duas vezes a quantidade necessária para depositar um revestimento de $40 \mathrm{~g} / \mathrm{m}^{2}$. Uma linha normal que tem a capacidade de processar de 70 a 120 toneladas/hora com uma massa de revestimento de $50 \mathrm{~g} / \mathrm{m}^{2}$ de cada lado que consumirá centenas de milhares de ampères durante uma hora de processamento. É fácil de ver porque os gastos com energia são componentes de custo muito importantes para unidades que processam grandes quantidades de chapas eletrogalvanizadas (AGA, 2016).

Os revestimentos eletrogalvanizado de forma contínua possuem resistência à corrosão similar ao galvanizado por imersão à quente. Uma massa de revestimento de $100 \mathrm{~g} / \mathrm{m}^{2}$ galvanizado por eletrolise proporcionará basicamente o mesmo nível de proteção contra corrosão de um revestimento galvanizado por imersão à quente, porém os revestimentos galvanizados por imersão à quente fornecem adicionalmente proteção por barreira através da passivação da camada ETA que produz um filme muito mais aderente e resistente do que o filme passivo que é formado nos aços galvanizados por eletrólise (AGA, 2016).

Adicionalmente as chapas de aços galvanizadas pela eletrólise contínua pode receber um tratamento adicional na superfície do revestimento metálico de fosfato de zinco e deposição eletrostática de um primer de aderência epóxi isocianato alifático bicomponente seguido de revestimento de pintura de acabamento em multicamadas. Obviamente, a resistência à corrosão necessária para proteger um painel de um veículo é maior do que a que pode ser oferecida somente pelo revestimento metálico. A aplicação deste sobre uma camada metálica eletrogalvanizada resulta em um sistema sinergético, cuja resistência à corrosão é maior do que a soma de seus componentes individuais. (CABANELAS, 2007)

\section{CONCLUSÃO}

Com a galvanização, pode-se obter um revestimento completo sobre uma peça em alguns minutos, enquanto que por outro processo seriam necessárias horas ou dias. As modernas linhas de zincagem contínua, por exemplo, produzem, no ritmo de $500 \mathrm{~m}^{2} / \mathrm{min}$, chapas com excelente qualidade de revestimento. Logo após a galvanização, a peça está pronta para ser utilizada, sem exigir preparação da superfície (lisa e brilhante), retoques ou pintura.

\section{REFERÊNCIAS}

AMERICAN GALVANIZERS ASSOCIATION. Duplex Systems. Disponível em: $<$ http://www.galvanizeit.org/corrosion/corrosion-protection/duplex-systems. $>$ Acesso em: 18 de mar. 2016.

AMERICAN GALVANIZERS ASSOCIATION. Hot-Dip Galvanizing. Disponível em: $<$ http://www.galvanizeit.org/hot-dip-galvanizing.>Acesso em: 18 de mar. 2016.

CABANELAS, I., COLLAZO, A., IZQUIERDO, M., NOVOA, X. R., PEREZ, C., "Influence of galvanised surface state on the duplex systems behavior". Corrosion Science, v. 49, pp. 1816-1832, Dez. 2007.

FAYALA, I., DHOUIBI, L., NOVOA, X.R., OUEZDOU, M. B.,“Effect of inhibitors on the corrosion of galvanized steel and on mortar properties". Cement \& Concrete Composites, v. 35, pp. 181-189, Dez. 2013. 
ICZ. Portal da Galvanização: galvanização por imersão à quente. Disponível em:<http://www.icz.org.br. >Acesso em: 18 de mar. 2016.

PEREZ, C., COLLAZO, A., IZQUIERDO, M., MERINO, P., NOVOA, X. R., "Comparative study between galvanized steel and tree duplex systems submitted to a weathering cyclic test." Corrosion Science, v. 44, pp. 481-500, Jun 2002

ROVENTI, G., BELLEZZE, T., GIULIANI, G., CONTI, C.,"Corrosion resistance of galvanized steel reinforcements in carbonated concrete: effect ofwet-dry cycles in tap water and in chloride solution on the passivating layer". Cement and Concrete Research, v. 65, pp. 7684, Dec. 2014

SERE, P. R., DEYA, C., ELSNER, C. I., DI SARLI, A. R., "Corrosion of painted galvanneal steel". $\quad$ Procedia Materials Science, v. 8, pp. 1-10, Feb. 2015

TUTIKIANI, B.F., HILGERTI, T., HOWLANDII, J.J., "Comparativo da aderência do concreto com aço sem proteção e o aço galvanizado a quente. Revista IBRACON, v.7, n.2, pp. 82-89, Apr 2014. 